\title{
Metal-fixed Multiwalled Carbon Nanotube Patterned Emitters Using Photolithography and Electrodeposition Technique**
}

Susumu Arai ${ }^{\mathrm{a}, *}$, Takashi Saito ${ }^{\mathrm{a}}$, Morinobu Endo ${ }^{\mathrm{b}}$

${ }^{a}$ Department of Chemistry and Material Engineering, Faculty of Engineering, Shinshu University, Nagano 380-8553, Japan

b Department of Electrical and Electronic Engineering, Faculty of Engineering, Shinshu University, Nagano 380-8553, Japan

*Corresponding author: Susumu Arai

Fax number: +81-26-269-5432 E-mail address: araisun@shinshu-u.ac.jp

Keywords: Carbon Nanotubes, Emitter, Electrodeposition, Photolithography, Copper

** This research was supported by the CLUSTER(the second stage) of the Ministry of Education, Culture, Sports, Science and Technology, Japan. 


\begin{abstract}
We have demonstrated that patterned $\mathrm{Cu}$-multiwalled carbon nanotube (MWCNT) composite emitters can be fabricated using a unique electrodeposition technique including a photolithography process. Well-regulated, patterned $\mathrm{Cu}-\mathrm{MWCNT}$ composite emitters $50 \mu \mathrm{m}$ in diameter were formed on the conductive substrates. The MWCNTs were fixed on the patterned composite emitters. The field emission properties were studied by a diode-type measurement system. The field emission electric field was relatively low $\left(1.5 \mathrm{~V} \mu \mathrm{m}^{-1}\right.$ for $1 \times 10^{-5} \mu \mathrm{A} \mathrm{cm}^{-2}, 2.5 \mathrm{~V} \mathrm{~m}^{-1}$ for 10 $\mu \mathrm{A} \mathrm{cm}{ }^{-2}$ ). These composite emitters can be expected to be applied in field emission displays and other field emission devices.
\end{abstract}


Flat panel displays (FPD) have been one of the driving forces behind the successful worldwide electronics industry. In particular, liquid crystal displays and plasma displays have been used for various purposes. The performance of these displays are currently very good, however, the problem of high power consumption needs to be resolved from an environment protection perspective. Organic electro-luminescence displays and field emission displays are expected to be next-generation displays with lower power consumption. The field emission display is spotlighted due to its superior display performance, such as fast response time, wide viewing angles, wide temperature range of operation, ultra-slim features and low power consumption. ${ }^{1,2}$ Many kinds of materials such as semiconductors and high-melting-point metals have been examined as field emission sources. ${ }^{3-5}$ Due to their high aspect ratios, chemical inertness and good electric conductivity, carbon nanotubes ${ }^{6,7}$ have been watched with keen interest as potential field emission electron sources. ${ }^{8-12}$

CNT-based field emitters have been fabricated by various methods such as direct growth ${ }^{13-15}$, screen printing, ${ }^{16-18}$, electrophoresis, ${ }^{19,20}$, and spray deposition. ${ }^{21}$ The direct chemical vapor deposition (CVD) growth method can easily control the alignment, density, diameter and length of CNTs. However, this method is limited by the scalability of the substrate size and the growth temperature. The screen printing method can realize large area deposition of CNTs easily, however, a substantial degradation of emission tips caused by oxygen out-gassed from the organic vehicles in the paste cannot be avoided. The electrophoresis method has the problem of weak adhesion. The spray deposition method can achieve large area deposition and can suppress degradation of emission tips. However, the problem of poor adhesion is a serious drawback for practical use. Thus, each method has several problems to overcome. Therefore, fabrication methods for CNT-based field emitters with good adhesion of CNTs to the substrate, scalability of substrate size, and suppression of degradation of emission tips are urgently needed. Furthermore, fabrication methods having the ability to pattern are required for wide use of the field emitters.

In the present study, we demonstrate a unique method for the fabrication of metal-fixed and patterned CNT field emitters. The fabrication technique utilizes photolithography and a composite plating.

\section{Experimental}

The CNTs used were commercially available (Showa Denko Co. Ltd.) vapor-grown multiwalled carbon nanotubes (MWCNTs), obtained via catalyst-assisted CVD, ${ }^{22}$ and heat-treated at $2800^{\circ} \mathrm{C}$ in argon for $30 \mathrm{~min}$. The MWCNTs were typically 100-200 nm in diameter and $20 \mu \mathrm{m}$ in length. A salfric copper plating bath $\left(0.85 \mathrm{~mol} \mathrm{\textrm {dm } ^ { - 3 }}\right.$ $\mathrm{CuSO}_{4} \cdot 5 \mathrm{H}_{2} \mathrm{O}+0.55 \mathrm{~mol} \mathrm{dm}{ }^{-3} \mathrm{H}_{2} \mathrm{SO}_{4}$ ) was used as the base bath. The MWCNTs did not disperse uniformly in the base bath; therefore, homogeneous dispersion of MWCNTs was achieved by the addition of a polyacrylic acid (mean molecular weight 5000) dispersant to the base bath with stirring. In the present study, the composition of the composite plating was $0.85 \mathrm{~mol} \mathrm{dm}^{-3} \mathrm{CuSO}_{4} \cdot 5 \mathrm{H}_{2} \mathrm{O}+0.55 \mathrm{~mol} \mathrm{dm}^{-3} \mathrm{H}_{2} \mathrm{SO}_{4}+2$ $\times 10^{-5} \mathrm{~mol} \mathrm{dm}^{-3}$ polyacrylic acid $+2 \mathrm{~g} \mathrm{dm}^{-3}$ MWCNTs. $^{23,24}$

The novel fabrication method for a patterned $\mathrm{Cu}$-MWCNT composite emitter is summarized in Fig.1. A pure copper substrate was coated with $25 \mu \mathrm{m}$ of a negative-type dry film photoresist and then patterned using a photomask with a matrix of $50 \mu \mathrm{m}$ diameter circles. The Cu-MWCNT composite was electroplated onto the 
substrate under galvanostatic conditions $\left(1 \mathrm{~A} \mathrm{dm}^{-2}\right)$ with aeration. After electroplating, the photoresist was stripped using a 4 mass $\% \mathrm{NaOH}$ aqueous solution, resulting in a patterned $\mathrm{Cu}-\mathrm{MWCNT}$ composite emitter. The appearance of the composite emitter was observed using a field-emission type scanning electron microscope (FE-SEM; JEOL JSM-7000F). Exclusive sample-preparation equipment (cross-section polisher; JEOL SM-09010) was used to prepare cross-sectional samples. The MWCNT content of the composite films was weighed directly. For the weight measurement, thick $\mathrm{Cu}-\mathrm{MWCNT}$ composite films (over $8 \mathrm{~g}$ in weigh) were electrodeposited. Subsequently, the copper matrix of the composite films was dissolved in a nitric acid. Then, the MWCNTs in the nitric acid solution were filtrated, dried and weighed. The electrical conductivity of the $\mathrm{Cu}$-MWCNT composite film was measured by a four-terminal method (a four point prove system) after removal from a stainless substrate.

A diode-type field emission property measurement system (ULVAC CN-EMS30) was used. The base pressure of the field emission chamber was around $10^{-5} \mathrm{~Pa}$. The patterned composite emitter (size: $1 \mathrm{~cm} \times 1 \mathrm{~cm}$ ) was fixed on a stainless steel cathode plate. A disk-type stainless steel anode with a facing surface area of $0.785 \mathrm{~cm}^{2}$ was placed parallel to the cathode. The gap between the anode and the surface of the patterned emitter was $1 \mathrm{~mm}$.

\section{Results and Discussion}

Figure 2 shows scanning electron microscopy (SEM) images of the patterned $\mathrm{Cu}-\mathrm{MWCNT}$ composite emitter. Each emitter is regularly spaced on the substrate surface (Fig. 2a). Each composite emitter is $50 \mu \mathrm{m}$ in diameter and $25 \mu \mathrm{m}$ in height (Fig. 2b). The size is controllable not only in terms of the diameter but also in height, by varying the mask patterns and electrodeposition conditions such as electrolysis time and current density. MWCNTs appear only on the patterned deposits and do not exist either on the undeposited areas or on the side walls of the patterned deposits (Fig. 2b). MWCNTs are embedded and fixed tightly in the copper matrix and the MWCNTs are uncovered (Fig. 2c). Figure 2d shows a cross-sectional SEM image of the $\mathrm{Cu}-\mathrm{MWCNT}$ composite emitter. The black areas are cross-sections of the MWCNTs. The MWCNTs are distributed homogeneously, and no significant voids and defects are observed.

The MWCNTs content is 0.4 mass\%, which is also controllable. The contact resistance between the MWCNTs and the conductive substrate is very important to make the field emission strength (i.e., the turn-on field) low. The electrical conductivity of the $\mathrm{Cu}-\mathrm{MWCNT}$ composite significantly affects the contact resistance. The measured value of the electrical conductivity is around $2 \mu \Omega \mathrm{cm}$, which is similar to that of pure copper. Therefore, the $\mathrm{Cu}$-MWCNT composite emitter can be expected to show a lower emission electric field compared to other emitters made using other fabrication methods such as screen printing and spray methods.

Figure 3 shows the relationship between the electric field and the emission current density for the $\mathrm{Cu}-\mathrm{MWCNT}$ composite emitters. An apparent increase in the emission current was observed at around $1.5 \mathrm{~V} \mathrm{\mu m}^{-1}$. The Fowler-Nordheim plot corresponding to Fig. 3 is nearly a straight line (Fig.4); therefore, the measured emission current must be the field emission current. The value of the field emission electric field $(1.5$ $\mathrm{V} \mu \mathrm{m}^{-1}$ at the current density of $1 \times 10^{-5} \mu \mathrm{A} \mathrm{cm} \mathrm{cm}^{-2}, 2.5 \mathrm{~V} \mu \mathrm{m}^{-1}$ at the current density of $10 \mu \mathrm{A} \mathrm{cm}^{-2}$ ) is relatively low as expected. The current density is around $50 \mu \mathrm{A} \mathrm{cm}^{-2}$ at an electric field of $3 \mathrm{~V} \mathrm{\mu m}^{-1}$. This value can be expected to increase by increasing the MWCNT density on the patterned composite emitters. Moreover the stability of the 
field emitter is very important. ${ }^{25}$ We will also study the stability of the emitter in future work.

\section{Conclusion}

We have demonstrated that patterned $\mathrm{Cu}-\mathrm{MWCNT}$ composite emitters can be fabricated. For this we used a unique electrodeposition technique including a photolithography process. Well-regulated, patterned $\mathrm{Cu}-\mathrm{MWCNT}$ composite emitters $50 \mu \mathrm{m}$ in diameter and $25 \mu \mathrm{m}$ in height were formed on the copper substrates. The MWCNTs were embedded in electrodeposited copper matrix and fixed tightly on the patterned composite emitters. The field emission properties were studied by a diode-type measurement system. The field emission electric field was relatively low $\left(1.5 \mathrm{~V} \mathrm{\mu m}^{-1}\right.$ at the current density of $1 \times 10^{-5} \mu \mathrm{A} \mathrm{cm}{ }^{-2}, 2.5 \mathrm{~V}^{-1}$ at the current density of $10 \mu \mathrm{A} \mathrm{cm}{ }^{-2}$ ). The field emission properties are expected to increase by increasing the MWCNT density on the patterned composite emitters. These composite emitters can be expected to be applied in field emission displays and other field emission devices. Furthermore, this fabrication approach represents a very versatile process to create a wide variety of patterned CNT-metal composite emitters. 


\section{References}

1. A.A. Talin, K.A. Dean, J.E. Jaskie, Solid State Electron, 45, 963 (2001).

2. S. Itoh, M. Tanaka, T. Tonegawa, J. Vac. Sci. Technol, B22/3, 1362 (2004).

3. F.S. Baker, A.R. Osborn, J. Williams, Nature, 239, 96 (1972).

4. O. Yavas, N. Suzuki, M. Takai, A. Hosono, S. Kawaguchi, Appl. Phys. Lett., 72, 2799 (1998).

5. C.A. Spindt, I. Brodie, L. Humphrey, E.R. Westerberg, J. Appl. Phys., 47, 5248 (1976).

6. A. Oberlin, M. Endo, T. Koyama, J. Cryst. Growth, 32, 335 (1976).

7. S. Iijima, Nature, 354, 56 (1991).

8. W.A. Heer, A. Chatelain, D. Ugarte, Science, 274, 1179 (1996).

9. R.H. Baughman, A.A. Zakhidov, W.A. Heer, Science, 297, 787 (1998).

10. Q.H. Wang, A.A. Setlur, J.M. Lauerhaas, J.Y. Dai, E.W. Seeling, R.P.H. Chang, Appl. Phys. Lett., 72, 2912 (1998).

11. W.B. Choi, Y.W. Jin, H.Y. Kim, S.J. Lee, M.J. Yun, J.H. Kang, Y.S. Choi, N.S. Park, N.S. Lee, J.M. Kim, Appl. Phys. Lett.,78, 1547 (2001).

12. J.M. Kim, W.B. Choi, N.S. Lee, J.J. Jung, Diamond Relat. Mater.,10, 1187 (2000).

13. Z.F. Ren, Z.P. Huang, J.W. Xu, J.H. Wang, P. Bush, M.P. Siegal, P. N. Provencio, Science, 282, 1105 (1998).

14. Y.H. Lee, Y.T. Jang, D.H. Kim, J.H. Kim, J.H. Ahn, B.K. Ju, Adv. Mater., 13, 489 (2001).

15. M.A. Guillorn, M.L. Simpsou, G.J. Bordonaro, V.I. Merkulov, L.R. Baylor, D.H. Lowndes, J. Vac. Sci. Technol., B19,573 (2001).

16. W.B. Choi, D.S. Chung, J.H. Kang, H.Y Kim, Y.W. Kim, I.T. Han, Y.H. Lee, J.E. Jung, N.S. Lee, G. S. Park, J. M. Kim, Appl. Phys. Lett., 75, 3129 (1999).

17. J.H. Park, J.H. Choi, J.S. Moon, D.G. Kushinov, J.B. Yoo, C.Y. Park, J.W. Nam, C.K. Lee, J.H. Park, D.H. Choe, Carbon, 43, 698 (2005).

18. Y.J. Jung, J.H. Park, S.Y. Jeon, P.S. Alegaonkar, A.S. Berdinsky, J.B. Yoo, C.Y. Park, Diamond Relat. Mater., 15, 1855 (2006).

19. B. Gao, G.Z. Yue, Q. Qiu, Y. Cheng, H. Shimoda, L. Fleming, O. Zhou, Adv. Mater., 13, 1770 (2001). 
20. W.B. Choi, Y.W. Jin, H.Y. Kim, S.J. Lee, M.J. Yun, J.H. Kang, Y.S. Choi, N.S. Park, N.S. Lee, J.M. Kim, Appl. Phys. Lett., 78, 1547 (2001).

21. Y.D. Lee, K.-S. Lee, Y.-H. Lee, B.-K. Ju, Appl. Surf. Sci., 254, 513 (2007).

22. M. Endo, CHEMTECH, 18, 568 (1988).

23. S. Arai, M. Endo, Electrochem. Solid-State Lett., 7, C25 (2004).

24. S. Arai, M. Endo, Electrochem. Communt., 5, 797 (2003).

25. M. Kumar, T. Okazaki, M. Hiramatsu, Y. Ando, Carbon, 45, 1899 (2007).

\section{Captions}

Figure 1. Schematic illustration of the fabrication procedure of the patterned $\mathrm{Cu}$-MWCNT composite emitters. A photoresist is laminated and patterned using a photolithographic technique, followed by the electrodeposition of the Cu-MWCNT composite. The photoresist is then removed by a stripper, resulting in patterned $\mathrm{Cu}-\mathrm{MWCNT}$ composite emitters.

Figure 2. SEM images of patterned Cu-MWCNT composite emitters. (a) low magnification; (b) the features of a Cu-MWCNT composite emitter; (c) surface morphology of an emitter; (d) cross-sectional image of an emitter.

Figure 3. The relationship between electric field and emission current density of the patterned $\mathrm{Cu}-0.4$ mass\%MWCNT composite emitters.

Figure 4. F-N plot corresponding to Fig.3. 
Conductive substrate

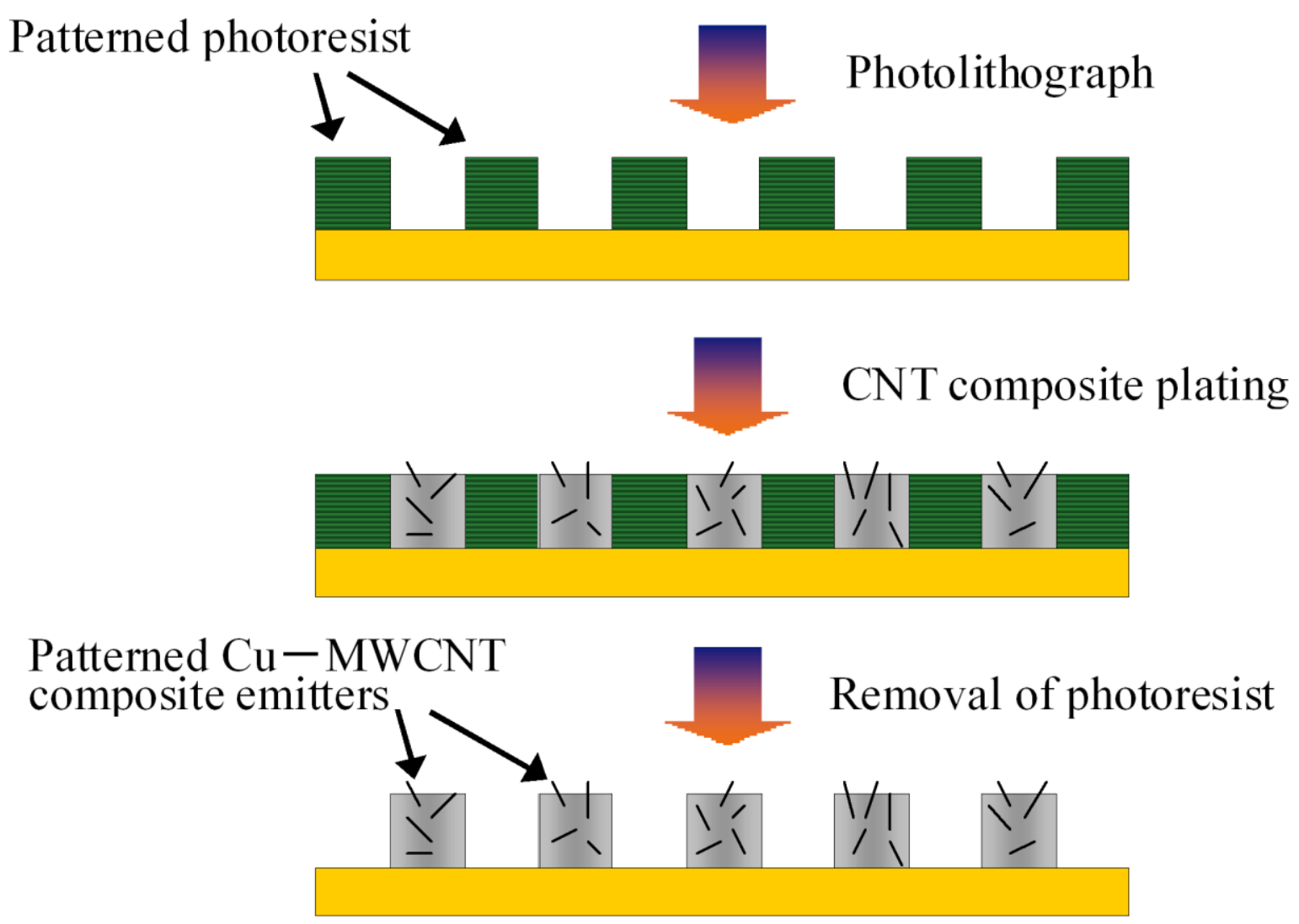

Figure 1. 


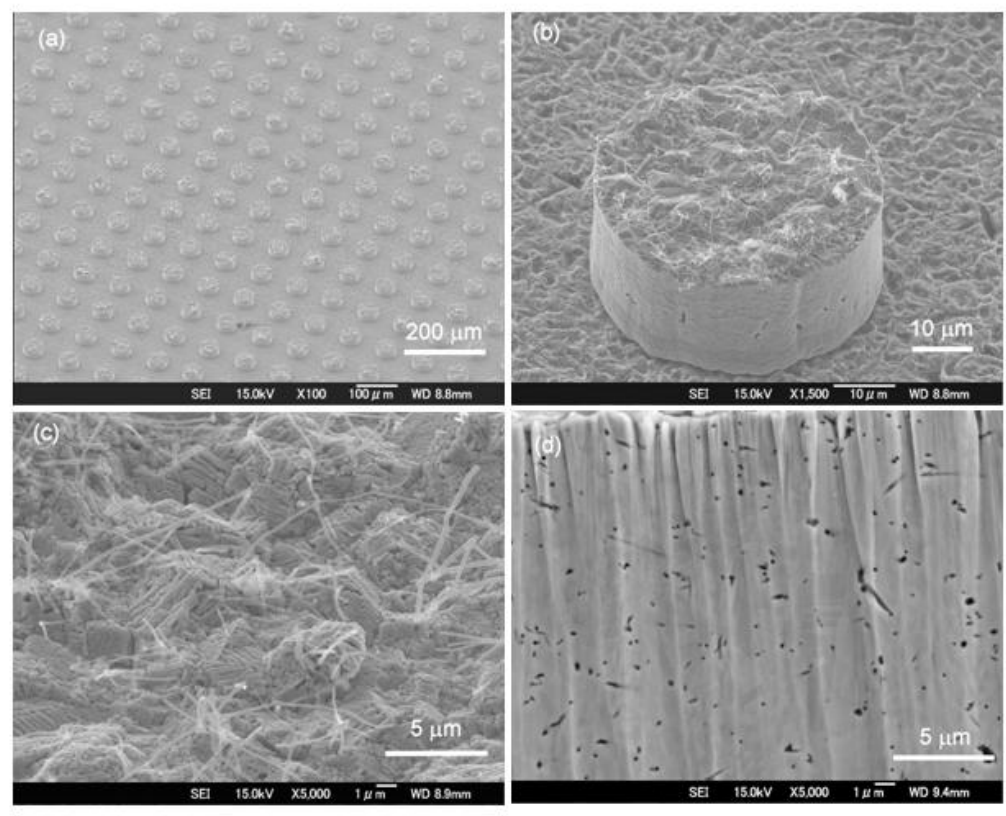

Figure 2. 


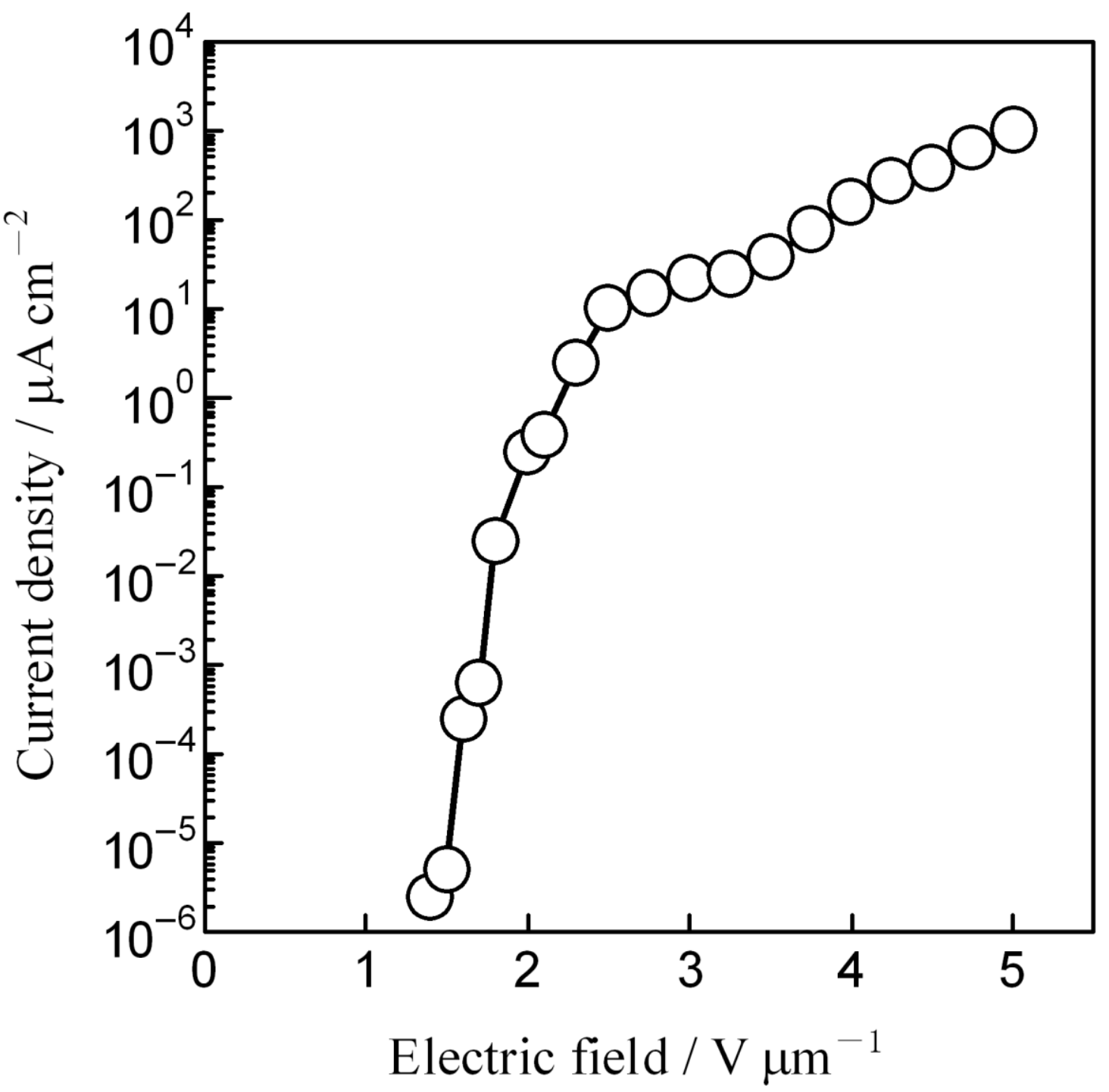

Figure 3. 


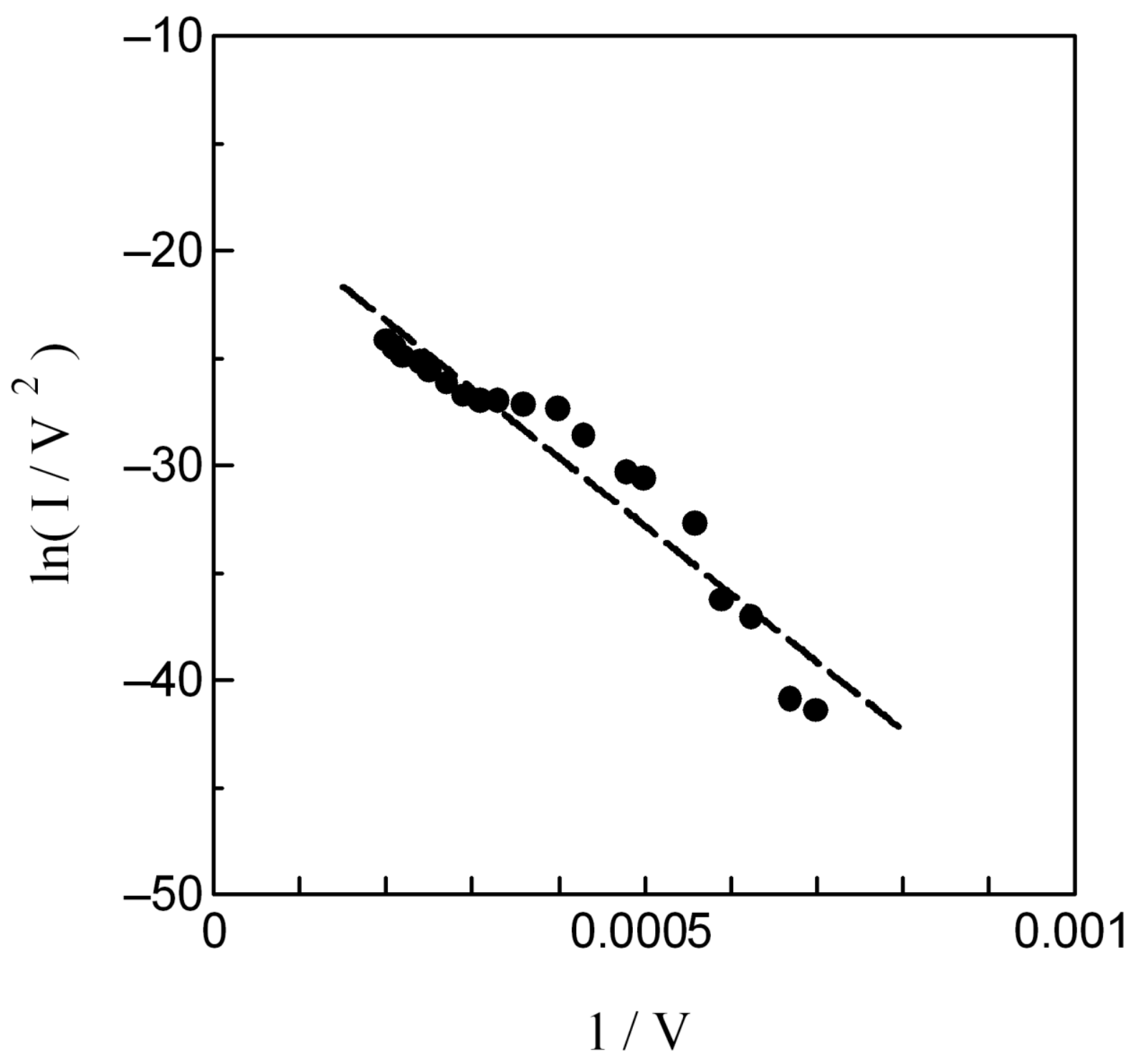

Figure 4. 